\title{
Effect of a hot water extract of Chlorella vulgaris on proliferation of IEC-6 cells
}

\author{
SEO-HYEON SONG ${ }^{*}$, IN-HYE KIM ${ }^{*}$ and TAEK-JEONG NAM \\ Department of Food Science and Nutrition, Pukyong National University 599-1, \\ Daeyeon 3-Dong, Nam-gu, Busan 608-737, Republic of Korea
}

Received November 16, 2011; Accepted December 29, 2011

DOI: 10.3892/ijmm.2012.899

\begin{abstract}
Chlorella vulgaris, a unicellular microalgae, exerts various biological effects; however their effect on proliferation signaling pathways in normal cells has not been studied. We investigated the effect of hot water extracts of Chlorella vulgaris (CVE) on cell proliferation and related signaling pathways in rat intestinal epithelial cells (IEC-6). CVE increased the expression of insulin-like growth factor-I receptor (IGF-IR) and the phosphorylation of focal adhesion kinase (FAK) and Src. In addition, CVE induced activation of the mitogen-activated protein kinase (MAPK) and phosphatidylinositol 3-kinase (PI3K)/Akt pathways. We verified the increased phosphorylation of extracellular-signal-related kinase (ERK) and Akt and the increased expression of the PI3K regulatory subunit p85. CVE also influenced the canonical Wnt pathway through increased expression of the nuclear $\beta$-catenin, cyclin D1. Tyr-397 of FAK mediates interactions with Src homology 2 (SH2) domains in a number of other signaling proteins, including PI3K, PLC- $\gamma$, Shc, Grb7, Src and Nck2. Because CVE induced FAK activation, FAK may affect the Wnt pathway. Addition of a FAK inhibitor decreased the expression of nuclear $\beta$-catenin, cyclin D1 and c-myc, and increased the expression of cytosolic $\beta$-catenin. We conclude that CVE stimulated proliferation of IEC- 6 cells via the MAPK, PI3K/Akt and canonical Wnt pathways, and that this affected the canonical Wnt pathway.
\end{abstract}

\section{Introduction}

Chlorella is a unicellular microalgae that is ubiquitous in freshwater environments. It contains highly nutritious substances such as protein, carbohydrates, vitamins, minerals, fatty acids, dietary fibers, and nucleic acids. The Chlorella polysaccharide,

Correspondence to: Dr Taek-Jeong Nam, Department of Food Science and Nutrition, Pukyong National University 599-1, Daeyeon 3-Dong, Nam-gu, Busan 608-737, Republic of Korea

E-mail:namtj@pknu.ac.kr

${ }^{*}$ Contributed equally

Key words: Chlorella vulgaris, proliferation, Wnt pathway $\beta$-1,3-glucan, exerts important biological effects, including immunomodulatory activities (1), free radical scavenging, and reduction of blood lipid levels (2). Thus, various healthpromoting effects have been suggested, including dioxin excretion (3), cadmium detoxification (4), hepatoprotection (5), and antitumor (6) and immunomodulatory activities (1). A hot water extract of Chlorella vulgaris (CVE) had an antitumor effect (7) and immunomodulatory activity $(8,9)$. To date, however, there has been little research regarding the effect of Chlorella on proliferation of normal cells. Most studies of the biological effects of Chlorella have been conducted in vivo.

Cell proliferation is modulated by intracellular signal transduction such as protein tyrosine kinases (PTKs). PTKs are involved in diverse cellular events, including differentiation, growth, metabolism, and apoptosis, and are classified as transmembrane receptor tyrosine kinases (RTK) or soluble cytoplasmic enzymes known as non-receptor tyrosine kinases (NRTK) (10). Insulin-like growth factor-I receptor (IGF-IR), an RTK, is essential for cell proliferation, growth, and differentiation. After binding of the ligand to the IGF-IR extracellular subunit, the receptors become activated resulting in phosphorylation of various substrates, including the p85 subunit of phosphatidylinositol 3-kinase (PI3K), and the adaptor proteins Shc and Grb2. Receptor activation leads to activation of the Ras/mitogen-activated protein kinase (MAPK) signaling pathway (11). In the PI3K-Akt pathway, activated PI3K phosphorylates phosphatidylinositol 4,5-bisphosphate [PI(4,5)P2], converting $\mathrm{PI}(4,5) \mathrm{P} 2$ to $\mathrm{PI}(3,4,5) \mathrm{P} 3$, a lipid second messenger (12). Akt binds to PI $(3,4,5) \mathrm{P} 3$ and changes conformation following phosphorylation by 3-phosphoinositide-dependent protein kinase-1 (PDK1). Activated Akt phosphorylates numerous substrates that are involved in various cellular functions (13). In mammals, three major MAPK pathways have been identified: extracellular-signal-related kinase (ERK), JNK, and p38 MAPK. The ERK (p42/44 MAPK) is known to be an intracellular checkpoint for cellular mitogenesis (14). Activated ERK can regulate targets in the cytosol and also translocate to the nucleus where it phosphorylates a variety of transcription factors that regulate gene expression. The JNK and p38 MAPK are activated by cellular stress, including UV irradiation, heat shock, high osmotic stress, lipopolysaccharide, and proinflammatory cytokines (15).

Focal adhesion kinase (FAK), a NRTK, associates with both integrins and growth factor receptors to control cell 
proliferation, survival, and motility (16). Tyrosine-397 is an autophosphorylation site of FAK and is critical for downstream signaling. It is also a binding site of PI3K, Grb-7, Shc, and other proteins and is one of the main phosphorylation sites for activation of FAK signaling (17).

The Wnt signaling pathways play a role in mitogenic stimulation, cell fate specification, and differentiation. The canonical Wnt pathway is regulated mainly by $\beta$-catenin (18). The binding of Wnt proteins to frizzled receptors leads to activation and subsequent inhibition of GSK- $3 \beta$ activity. The level of cytosolic $\beta$-catenin is then increased, and it is translocated to the nucleus, where it interacts with the $\mathrm{T}$ cell-specific factor/lymphoid enhancer-binding factor (TCF/LEF) family of transcription factors and activates target genes such as c-myc and cyclins (19).

In this study, we showed that an extract of $C$. vulgaris (named CVE) has proliferative effects on intestinal epithelial cells (IEC-6) cells. We determined the intracellular mechanism induced by CVE and focused on the IGF-IR, FAK, and the canonical Wnt signaling pathways, which are involved in the regulation of cellular proliferation and differentiation.

\section{Materials and methods}

Preparation of CVE. Dried, powdered chlorella (C. vulgaris) was purchased from Daesang Corp. Well Life (Seoul, Republic of Korea). The powder was extracted with distilled water for $15 \mathrm{~min}$ at $121^{\circ} \mathrm{C}$ in an autoclave. Centrifugation at $8,000 \mathrm{rpm}$ for $30 \mathrm{~min}$ at $4^{\circ} \mathrm{C}$ was used to remove insoluble materials from extracts. After filtering, the solvent was evaporated in a vacuum condenser and the residue was lyophilized. The yield of dried CVE was $17.4 \%$, and it was stored at $-20^{\circ} \mathrm{C}$.

Sodium dodecyl sulfate-polyacrylamide gel electrophoresis (SDS-PAGE). CVE was analyzed by SDS-PAGE on $15 \%$ gels according to the method of Laemmli (20). After electrophoresis, gels were subjected to Coomassie brilliant blue (CBB) staining for proteins, and periodic acid-Schiff (PAS) staining for glycoproteins (GelCode glycoprotein staining kit, Pierce Co., Ltd., Rockford, IL, USA).

Cell culture. Rat small intestine epithelial cells (IEC-6, ATCC CRL-1592) were obtained from the American Type Culture Collection (Rockville, MD, USA). The cells were cultured in Dulbecco's modified Eagle's medium (DMEM) supplemented with $10 \%$ fetal bovine serum (HyClone, Inc., South Logan, UT, USA) and antibiotics. The cultures were maintained in a humidified incubator at $37^{\circ} \mathrm{C}$ under an atmosphere containing $5 \% \mathrm{CO}_{2}$, and the medium was replaced every other day.

Cell proliferation assay. The effects of various CVE concentrations on cell proliferation were determined colorimetrically after $24 \mathrm{~h}$ using the 3-(4,5-dimethylthiazol-2-yl)-5-(3-carboxymethoxy-phenyl)-2-(4-sulfonyl)-2H-tetrazolium (MTS) assay with the Cell Titer 96 Aqueous One Solution reagent (Promega, Madison, WI, USA). Cells were seeded onto 48 -well plates at $2 \times 10^{4}$ cells/well. After $24 \mathrm{~h}$ of incubation, cells were maintained in serum-free medium (SFM) for $12 \mathrm{~h}$. The medium was replaced with fresh SFM medium containing $\mathrm{CVE}$, and the cells were incubated for an additional $24 \mathrm{~h}$. The cells were exposed to MTS assay solution at $37^{\circ} \mathrm{C}$ for $30 \mathrm{~min}$,
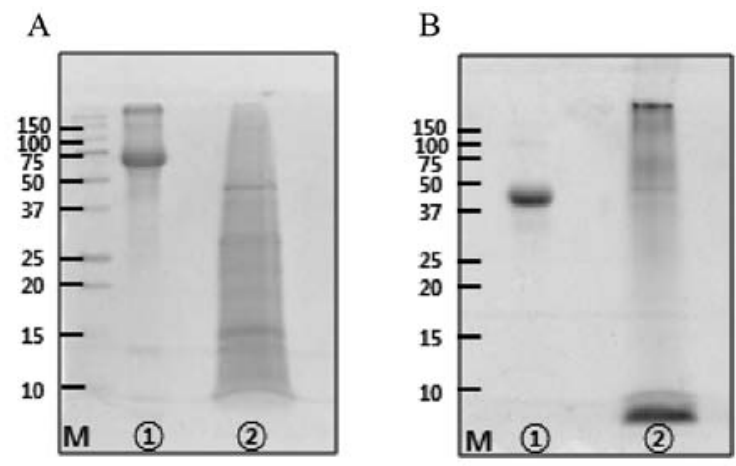

Figure 1. SDS-PAGE bands of CVE. (A) Coomassie blue staining. 1, positive control (albumin, $10 \mu \mathrm{g} / \mathrm{ml}) ; 2$, CVE $(50 \mu \mathrm{g} / \mathrm{ml})$. (B) PAS staining. 1, positive control (horseradish peroxidase, $10 \mu \mathrm{g} / \mathrm{ml}) ; 2$, CVE $(50 \mu \mathrm{g} / \mathrm{ml})$. M, protein standard.

and the optical density at $490 \mathrm{~nm}$ was measured using a microplate reader. The $\mathrm{OD}_{490}$ values of control cells were designated as $100 \%$.

Treatment with a FAK inhibitor. The FAK inhibitor 14, 1,2,4,5-benzenetetramine tetrahydrochloride was obtained from Tocris Bioscience (Ellisville, MO, USA). It was stored as a stock solution at $20 \mathrm{mM}$ at $-20^{\circ} \mathrm{C}$. Cells were pretreated with $2 \mu \mathrm{M}$ FAK inhibitor for $1 \mathrm{~h}$ and then incubated for $24 \mathrm{~h}$ as above.

Preparation of whole cell protein lysates. Cells were plated onto $100-\mathrm{mm}$ dishes and cultured to $80 \%$ confluence at $37^{\circ} \mathrm{C}$, followed by incubation for $24 \mathrm{~h}$ in SFM or SFM containing $12.5,25$, or $50 \mu \mathrm{g} / \mathrm{ml} \mathrm{CVE}$. Cells were then washed in cold phosphate buffer solution (PBS) and lysed with extraction buffer (1\% NP-40, $0.25 \%$ sodium deoxycholate, $1 \mathrm{mM}$ EGTA, $150 \mathrm{mM} \mathrm{NaCl}, 50 \mathrm{mM}$ Tris-HCl, $\mathrm{pH}$ 7.5) containing protease inhibitors $(1 \mathrm{mg} / \mathrm{ml}$ aprotinin, $1 \mathrm{mg} / \mathrm{ml}$ leupeptin, $1 \mathrm{mg} / \mathrm{ml}$ pepstatin A, $200 \mathrm{mM} \mathrm{Na}_{3} \mathrm{VO}_{4}, 500 \mathrm{mM} \mathrm{NaF}, 100 \mathrm{mM} \mathrm{PMSF}$ ) on ice. The extracts were centrifuged at $12,000 \mathrm{rpm}$ for $10 \mathrm{~min}$ and the supernatant was used in western blotting.

Extraction of cytosol lysate. Cells were treated and harvested as described above, and lysed with extraction buffer $(20 \mathrm{mM}$ HEPES-KOH, pH 7.5, $10 \mathrm{mM} \mathrm{KCl}, 1.5 \mathrm{mM} \mathrm{MgCl}, 1 \mathrm{mM}$ EDTA, $1 \mathrm{mM}$ EGTA, $1 \mathrm{mM}$ DTT, $0.1 \mathrm{mM}$ PMSF, $250 \mathrm{mM}$ sucrose) containing protease inhibitors $(1 \mathrm{mg} / \mathrm{ml}$ aprotinin, $1 \mathrm{mg} / \mathrm{ml}$ leupeptin, $1 \mathrm{mg} / \mathrm{ml}$ pepstatin A, $200 \mathrm{mM} \mathrm{Na}_{3} \mathrm{VO}_{4}$, $500 \mathrm{mM} \mathrm{NaF}, 100 \mathrm{mM}$ PMSF) on ice. The extracts were centrifuged at $3,500 \mathrm{x}$ g for $10 \mathrm{~min}$, and the supernatants were collected and further centrifuged at $1,400 \mathrm{x}$ g for $15 \mathrm{~min}$.

Extraction of nuclear lysates. Cells were treated and harvested as described above, lysed with hypotonic lysis buffer $(10 \mathrm{mM}$ HEPES, pH 7.9, $10 \mathrm{mM} \mathrm{KCl}, 1.5 \mathrm{mM} \mathrm{MgCl}_{2}$ ), and incubated for $15 \mathrm{~min}$ on ice. Cells were then further lysed by the addition of $2.5 \%$ NP-40. After $10 \mathrm{~min}$, nuclei were collected by centrifugation at $500 \mathrm{x} \mathrm{g}$ for $5 \mathrm{~min}$ at $4^{\circ} \mathrm{C}$. Nuclear proteins were resuspended in extraction buffer (10 mM HEPES, pH 7.9, $100 \mathrm{mM} \mathrm{NaCl}, 1.5 \mathrm{mM} \mathrm{MgCl}_{2}, 0.1 \mathrm{mM}$ EDTA, $0.1 \mathrm{mM}$ DTT).

Western blot analysis. Proteins (50 $\mu \mathrm{g})$ were separated using $10 \%$ SDS-PAGE and transferred to a PVDF membrane 
Table I. Proximate composition of Chlorella vulgaris and hot water extract of Chlorella vulgaris (CVE).

\begin{tabular}{lccccc}
\hline & Moisture $(\%)$ & Crude protein $(\%)$ & Crude lipid $(\%)$ & Crude ash $(\%)$ & Carbohydrate $(\%)^{\mathrm{a}}$ \\
\hline Chlorella vulgaris & $3.48 \pm 0.03$ & $54.53 \pm 0.11$ & trace & $3.88 \pm 0.02$ & 38.11 \\
& - & $(56.43)$ & $($ trace $)$ & $(4.02)$ & $(39.44)$ \\
CVE & $5.17 \pm 0.08$ & $61.41 \pm 0.18$ & trace & $14.24 \pm 0.10$ & 19.18 \\
& - & $(64.58)$ & $($ trace $)$ & $(14.98)$ & $(20.17)$ \\
\hline
\end{tabular}

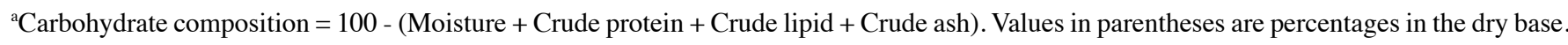

A

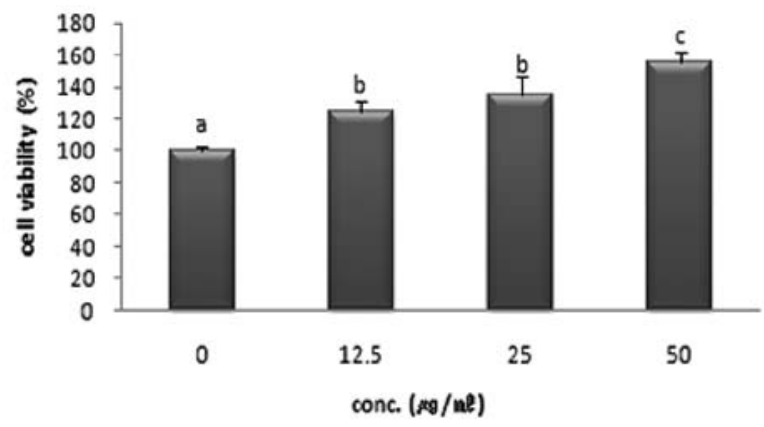

B

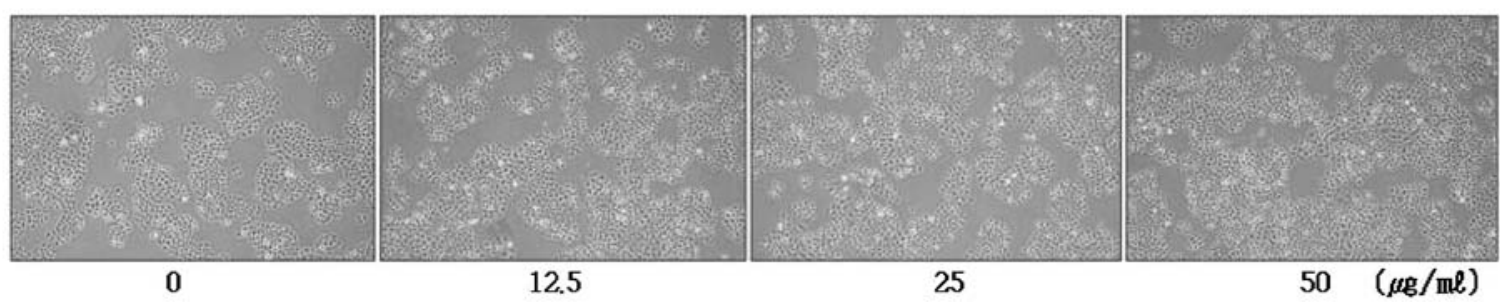

Figure 2. Proliferative effect of CVE on IEC-6 cells. (A) Cells were seeded in 48-well plates at a density of $2 \times 10^{4}$ cells/well with medium supplemented with $10 \%$ FBS. After incubation for $24 \mathrm{~h}$, cells were serum-starved for $12 \mathrm{~h}$ and then treated with CVE at the indicated concentrations for $24 \mathrm{~h}$. The results are the mean \pm SD or three independent experiments. (B) Cells were treated with various concentrations of CVE for $24 \mathrm{~h}$. After $24 \mathrm{~h}$, the morphologies were photographed using phase-contrast optics. Photographs were captured at a 400 magnification.

(Millipore, Billerica, MA, USA). Membranes were blocked with $1 \%$ bovine serum albumin (BSA) in TBS-T $(10 \mathrm{mM}$ Tris- $\mathrm{HCl}, 150 \mathrm{mM} \mathrm{NaCl}, \mathrm{pH}$ 7.5, 0.1\% Tween-20) and then incubated overnight with the indicated primary antibodies (diluted 1:1,000 or 1:500) in TBS-T containing 1\% BSA with gentle shaking at $4^{\circ} \mathrm{C}$. The secondary antibody was a horseradish peroxidase (HRP)-conjugated goat anti-mouse or rabbit anti-goat or goat anti-rabbit antibody (diluted 1:10,000). Signals were detected using an enhanced chemiluminescent (ECL) western blotting kit (Thermo Fisher Scientific, Inc., Rockford, IL, USA).

Statistical analysis. Multiple mean values were compared for significance using an analysis of variance (ANOVA) with the SPSS statistical software package. Values of $\mathrm{P}<0.05$ were considered significant.

\section{Results}

Effect of CVE on IEC-6 cell proliferation. The CVE was subjected to $15 \%$ SDS-PAGE, and gels were subjected to CBB protein staining (Fig. 1A) and PAS glycoprotein staining
(Fig. 1B). We confirmed the presence of a wide range of glycoprotein and protein bands and named this extract ' $C V E$ '. As shown in Table I, CVE was composed mainly of crude protein; when dried, it was $64.58 \%$ crude protein, $20.17 \%$ carbohydrate, and $14.98 \%$ crude ash. An MTS assay was performed to assess the proliferative effect of CVE on IEC-6 cells. Treatment with 12.5, 25 and $50 \mu \mathrm{g} / \mathrm{ml} \mathrm{CVE}$ for $24 \mathrm{~h}$ increased the cell viability by $124.0,135.4$ and $155.0 \%$, compared to controls (Fig. 2A). This increase in population was confirmed via photomicrography (Fig. 2B).

CVE induces increased expression of IGF-IR and phosphorylation of FAK/Src. To determine the signal transduction pathways induced by CVE, the level of IGF-IR expression was assayed by western blotting. CVE treatment for $24 \mathrm{~h}$ resulted in increased levels of pro-IGF-IR and IGF-IR (Fig. 3A). IGF-IR stimulates growth of many cell types and blocks apoptosis (21). Activation of IGF-IR is a particularly important survivalpromoting signal during development.

We also examined the expression of FAK and Src, intracellular PTKs that act to promote cell motility, cell cycle progression, and cell survival. The level of FAK and Src phosphorylation was 
A

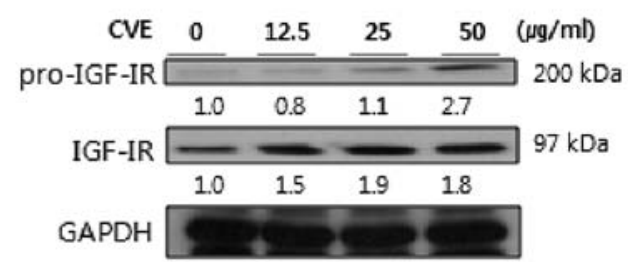

B

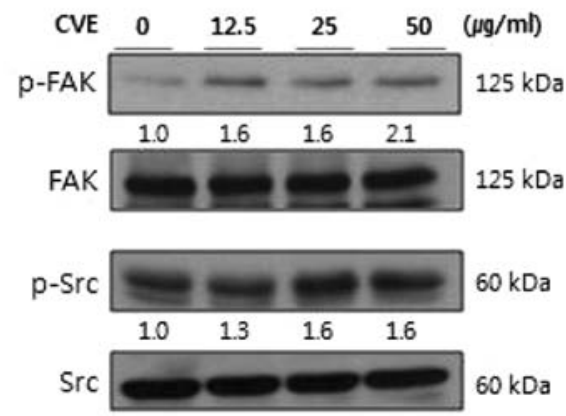

Figure 3. Effect of CVE treatment on the level of IGF-IR, FAK and Src protein expression in IEC-6 cells. Cells were treated with CVE after preincubation with serum-free medium for $12 \mathrm{~h}$. Whole cell extracts were prepared and analyzed by western blotting using anti-IGF-IR $\beta$, anti-phospho-FAK, anti-FAK, anti-phospho-Src, anti-Src and anti-GAPDH antibodies.

increased compared with controls (Fig. 3B). For quantification, densitometry of protein bands was performed with the Science Lab 2005 software (Fujifilm, Japan).

CVE stimulates MAPK activation and the PI3K/Akt pathway. To investigate the downstream signals that are regulated by IGF-IR and FAK activation, the expression of ERK1/2, JNK, and $\mathrm{p} 38$ was determined by western blotting. With CVE treatment for $24 \mathrm{~h}$, the level of ERK1/2 (Fig. 4A), but not of JNK or p38 (data not shown), phosphorylation was increased compared with controls. The PI3K regulatory subunit levels and the Akt phosphorylation were increased by CVE treatment (Fig. 4B).

CVE induces activation of the canonical Wnt pathway. The expression of the major components involved in the canonical Wnt pathway, including cytosolic $\beta$-catenin, nuclear $\beta$-catenin, cyclin D1, and c-myc, was determined by western blotting. CVE treatment for $24 \mathrm{~h}$ resulted in increased levels of nuclear $\beta$-catenin and cyclin D1 protein compared with controls (Fig. 5). However, the levels of cytosolic $\beta$-catenin and c-myc were unchanged.

Pretreatment of the FAK inhibitor suppresses CVE-induced proliferation. To confirm that the FAK inhibitor suppresses CVE-induced proliferation, an MTS assay and western blot analysis were performed. Pretreatment with a FAK inhibitor for $1 \mathrm{~h}$, followed by addition of CVE $(25 \mu \mathrm{g} / \mathrm{ml})$ for $24 \mathrm{~h}$, caused a decrease in cell viability identical to that of controls (Fig. 6A). FAK phosphorylation decreased slightly compared with the CVE-treated, but not the control, groups (Fig. 6B).

Inhibition of FAK effects on the canonical Wnt pathway. Because CVE increased the level of FAK phosphorylation in

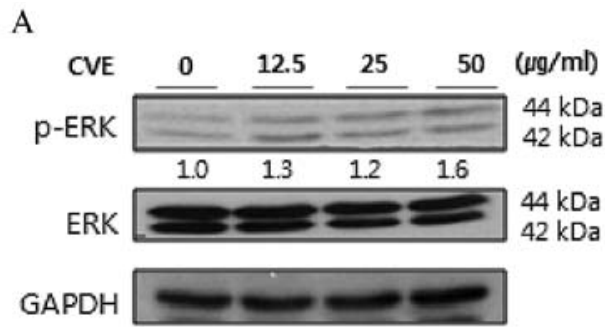

B

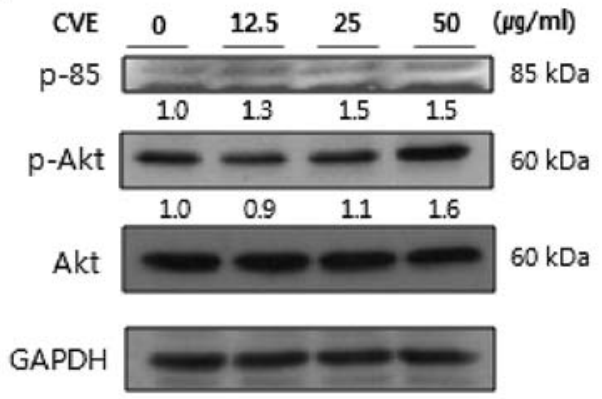

Figure 4. Effects of CVE treatment on the MAPK pathway and the PI3K/Akt pathway. Cells were treated with CVE after preincubation with serum-free medium for $12 \mathrm{~h}$. (A) Whole cell extracts were prepared and analyzed by western blotting using anti-phospho-ERK1/2, anti-ERK, anti-phospho-JNK, anti-JNK, anti-phospho-p38, anti-p38 and anti-GAPDH antibodies. (B) Whole cell extracts were analyzed by western blotting using anti-p $85 \alpha$, antiphospho-Akt1/2/3, anti-Akt1 and anti-GAPDH antibodies.

IEC-6 cells, we attempted to confirm whether FAK activation influences the expression of the major components of the canonical Wnt pathway. The data suggest that the levels of cytosolic $\beta$-catenin were increased and those of nuclear $\beta$-catenin were decreased after pretreatment with a FAK inhibitor (Fig. 7). Cyclin D1 and c-myc levels were also decreased.

\section{Discussion}

Chlorella is an attractive food source because it is high in protein and other essential nutrients ( $45 \%$ protein, $20 \%$ fat, $20 \%$ carbohydrate, $5 \%$ fiber, and $10 \%$ minerals and vitamins). We purchased Chlorella (C. vulgaris) from Daesang Corp. Well Life (Seoul, Republic of Korea) and extracted it with hot water $\left(121^{\circ} \mathrm{C}, 15 \mathrm{~min}\right)$. This hot water extract (CVE) consisted of protein and glycoprotein, as determined by Coomassie blue and PAS staining (Fig. 1). It contained approximately $64.58 \%$ crude protein, $20.17 \%$ carbohydrate, and $14.98 \%$ crude ash (Table I). In general, Chlorella contains about $20 \%$ crude lipids, but crude lipid was not detected in this study. The aim of this study was to determine whether CVE could induce proliferation of IEC- 6 cells and to identify the signals related to this proliferation process. In an MTS assay, CVE exhibited a dosedependent effect on the proliferation of IEC-6 cells (Fig. 2). Therefore, we examined the mechanism underlying this effect. Cell proliferation is regulated by multiple signaling pathways. We focused on the IGF-IR, FAK, and canonical Wnt pathways.

Activated IGF-IR plays a pivotal role in tissue homeostasis and regulation of cell proliferation, differentiation, and migration during development in adults. It is a particularly important survival-promoting signal (22). Our results showed that CVE increased the expression of pro-IGF-IR and IGF-IR (Fig. 3A). 

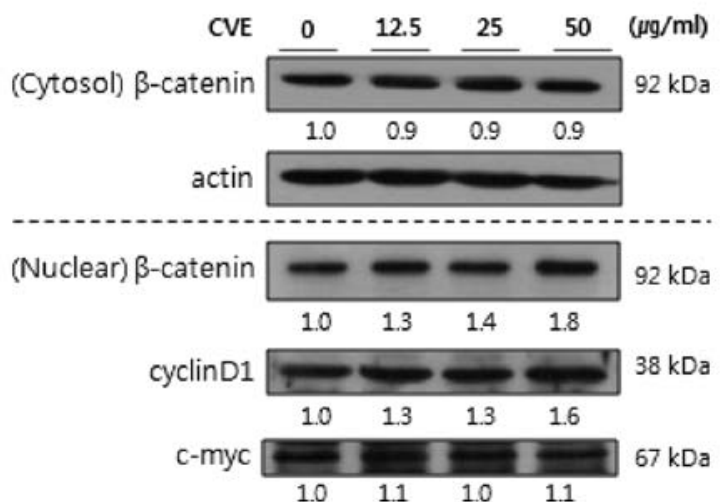

Figure 5. Effects of CVE treatment on the expression of canonical Wnt pathway regulators in IEC-6 cells. Cells were treated with CVE after preincubation with SFM for $12 \mathrm{~h}$. The Cytosolic fraction and the nuclear fraction were prepared and analyzed by western blotting using anti- $\beta$-catenin, anti-cmyc, anti-cyclin D1 and anti-actin antibodies.

A

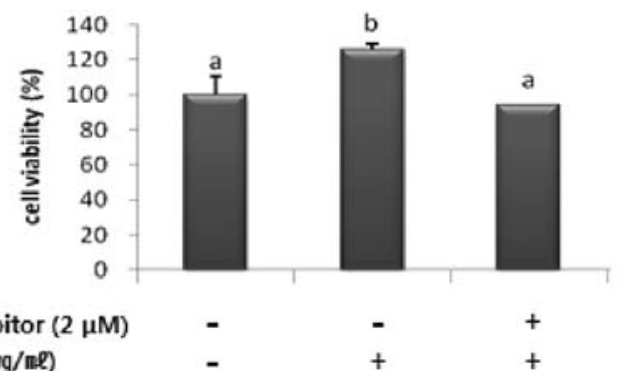
FAK inhibitor (2 ${ }^{2}$ CVE $(25 \mu g / m \ell)$

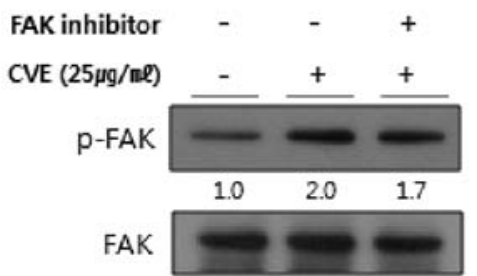

Figure 6. Effect of FAK inhibitor on cell proliferation induced by CVE treatment in IEC-6 cells. (A) Cells were seeded onto 96 -well plates at $1.5 \times 10^{4}$ cells/well in $100 \mu \mathrm{l}$ medium. After $24 \mathrm{~h}$, cells were maintained in serumfree medium for $12 \mathrm{~h}$. After pre-treatment with FAK inhibitor $(2 \mu \mathrm{M})$, cells were incubated with CVE for $24 \mathrm{~h}$. Cell viability was measured with the MTS assay kit according to the manufacturer's instructions. Values are the mean \pm SD. Different letters represent significantly different percentages by the Duncan's multiple range test. (B) Whole cell extracts were prepared and analyzed by western blotting using anti-phospho-FAK, anti-FAK antibodies.

FAK is known to participate in various intracellular signal transduction pathways and it plays a role in endothelial cell motility and survival (23). In normal cells, FAK/Src signals can control cell survival, proliferation, and cell motility. Both FAK/Src signaling and IGF-IR can stimulate the PI3K/ Akt and MAPK pathways (16,24). We confirmed that CVE increased the phosphorylation FAK and Src (Fig. 3B). Thus, CVE activated ERK1/2, an important mediator that regulates cell growth and differentiation (Fig. 4A). In contrast, CVE treatment did not trigger activation of JNK or p38 (data not shown), both of which are involved in the cell death pathway and the response to oxidative stress. Therefore, CVE induced cell proliferation via the activation of MAPK (ERK1/2, p38, JNK), especially ERK1/2. We also confirmed that CVE

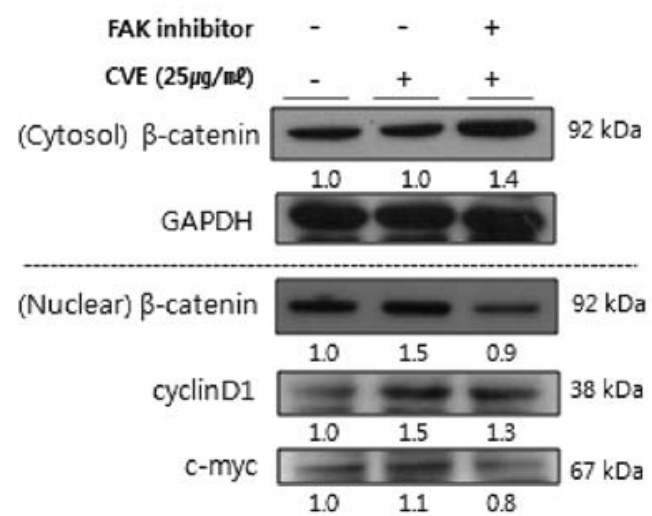

Figure 7. Effect of the FAK inhibitor on expression of canonical Wnt pathway regulators in IEC-6 cells. Cells were pre-treated with FAK inhibitor $(2 \mu \mathrm{M})$ and then incubated with CVE for $24 \mathrm{~h}$. The cytosolic and nuclear fractions were prepared and analyzed by western blotting using anti- $\beta$-catenin, anti-cmyc, anti-cyclin D1 and anti-GAPDH antibodies.

increased both the levels of the PI3K regulatory subunit of $\mathrm{p} 85$ and Akt phosphorylation (Fig. 4B).

Promotion of cell proliferation and division depends on intracellular signaling pathways, such as the Wnt signal transduction pathway. We assumed that CVE-induced cell proliferation was involved in the canonical Wnt signaling pathway (18). CVE increased the expression of cyclin D1 but did not alter that of c-myc, which is an important targeting protein. Translocation of $\beta$-catenin from the cytosol to the nucleus is necessary to induce expression of target genes. We found that expression of cytosolic $\beta$-catenin was unchanged but expression of nuclear $\beta$-catenin was increased by CVE treatment (Fig. 5). These results suggest that CVE-induced proliferation of IEC- 6 cells causes translocation of $\beta$-catenin from the cytosol to the nucleus subsequent to an increase in cyclin D1 level.

Gastrointestinal damage is a side-effect of non-steroidal anti-inflammatory drugs (NSAID) and anticancer chemotherapeutic agents $(25,26)$. Therefore, discovery of novel mitigative compounds is necessary. PHY906, a four-herb Chinese medicine formula, was found to decrease the gastrointestinal toxicity induced by the chemotherapeutic drug CPT-11 (27). Furthermore, compounds have been isolated from Anchusa strigosa root (28), Camellia sinensis (29), and Picrorhiza kurroa (30). In this study, we showed that CVE stimulated the proliferation of normal intestinal epithelial cells. In addition, we determined that this effect was related to the IGF-IR, FAK, and canonical Wnt signaling pathways. Thus, CVE-induced cell proliferation was decreased by a FAK inhibitor (Fig. 6). FAK has been proposed as a novel target for anticancer drugs (31). These data suggest that CVE may be an ideal adjuvant for prevention of gastrointestinal damage.

\section{Acknowledgements}

This study was undertaken as part of a larger project titled 'Development for Novel Biofunctional Protein Source from Marine Algae Produced in the Coastal Area of Busan' and funded by the Ministry of Land, Transport and Maritime Affairs, Republic of Korea. 


\section{References}

1. Lee HS, Lee SH, Mun HC and Lee HY: Screening of the immuno-stimulatory activity of the marine alga Chlorella capsulata. KSBB J 18: 19-24, 2003

2. Spolaore P, Joannis-Cassan CJ, Duran E and Isambert A Commercial applications of microalgae. J Biosci Bioeng 101: 87-96, 2006.

3. Morita K, Matsueda T, Iida T and Hasegawa T: Chlorella accelerates dioxin excretion in rats. J Nutr 129: 1731-1736, 1999.

4. Kim YJ, Kwon S and Kim MK: Effect of Chlorella vulgaris intake on cadmium detoxification in rats fed cadmium. Nutr Res Pract 3: 89-94, 2009.

5. Peng HY, Chu YC, Chen SJ and Chou ST: Hepatoprotecion of Chlorella against carbon tetrachloride-induced oxidative damage in rats. In Vivo 23: 747-754, 2009.

6. Tanaka K, Yamada A, Noda K, Hasegawa T, Okuda M, Shoyama Y and Nomoto K: A novel glycoprotein obtained from Chlorella vulgaris strain CK22 shows antimetastatic immunopotentiation. Cancer Immunol Immunother 45: 313-320, 1998

7. Konishi F, Mitsuyama M, Okuda M., Tanaka K, Hasegawa T and Nomoto K: Protective effect of an acidic glycoprotein obtained from culture of Chlorella vulgaris against myelosuppression by 5-fluorouracil. Cancer Immunol Immunother 42: 268-274, 1996.

8. An HJ, Rim HK, Jeong HJ,Hong SH,Um JY and Kim HM: Hot water extracts of Chlorella vulgaris improve immune function in proteindeficient weanling mice and immune cells. Immunophamacol Immunotoxicol 32: 585-592, 2010.

9. Hsu HY, Jeyashoke N, Yeh CH, Song YJ, Hua KF and Chao LK: Immunostimulatory bioactivity of algal polysaccharides from Chlorella pyrenoidosa activates macrophages via toll-like receptor 4. J Agric Food Chem 58: 927-936, 2010

10. Arora A and Scholar EM: Role of tyrosine kinase inhibitors in cancer therapy. J Pharmacol Exp Ther 315: 971-979, 2005.

11. Annunziata M, Cranata R and Ghigo E: The IGF system. Acta Diabetologica 48: 1-9, 2010.

12. Alessi DR, James SR, Downes CP, Holmes AB, Gaffney PJ, Reese CB and Cohen P: Characterization of a 3-phosphoinositidedependent protein kinase which phosphorylates and activates protein kinase $\mathrm{B} \alpha$. Curr Biol 7: 261-269, 1997.

13. Manning BD and Cantley LC: AKT/PKB signaling: navigating downstream. Cell 129: 1261-1274, 2007.

14. Zhang W and Liu HT: MAPK signal pathways in the regulation of cell proliferation in mammalian cells. Cell Res 12: 9-18, 2002.

15. Kyriakis JM and Avruch J: Mammalian mitogen-activated protein kinase signal transduction pathways activated by stress and inflammation. Physiol Rev 81: 807-869, 2001.

16. Mitra SK and Schlaepfer DD: Integrin-regulated FAK-Src signaling in normal and cancer cells. Curr Opin Cell Biol 18: 516-523, 2006
17. Hanks SK, Ryzhova L, Shin NY and Brabek J: Focal adhesion kinase signaling activities and their implications in the control of cell survival and motility. Front Biosci 8: d982-d996, 2003.

18. Pinto D, Gregorieff A, Begthel $\mathrm{H}$ and Clevers H: Canonical Wnt signals are essential for homeostasis of the intestinal epithelium. Genes Dev 17: 1709-1713, 2003.

19. Willert K and Nusse R: Beta-catenin: a key mediator of Wnt signaling. Curr Opin Genet Dev 8: 95-102, 1998.

20. Laemmli UK: Cleavage of structural proteins during the assembly of the head of bacteriophage T4. Nature 15: 680-685, 1970.

21. Frattali AL and Pessin JE: Molecular defects of insulin/IGF-I receptor transmembrane signaling. Ann NY Acad Sci 687: 77-89, 1993.

22. Torres Aleman I: Role of insulin-like growth factors in neuronal plasticity and neuroprotection. Adv Exp Med Biol 567: 243-258, 2005.

23. Avraham HK, Lee TH, Koh Y, Kim TA, Jiang S, Sussman M, Samarel AM and Avraham S: Vascular endothelial growth factor regulates focal adhesion assembly in human brain microvascular endothelial cells through activation of the focal adhesion kinase and related adhesion focal tyrosine kinase. J Biol Chem 19: 36661-36668, 2003.

24. Shelton JG, Steelman LS, White ER and McCubrey JA: Synergy between PI3K/Akt and Raf/MEK/ERK pathways in IGF-1R mediated cell cycle progression and prevention of apoptosis in hematopoietic cells. Cell Cycle 3: 372-379, 2004.

25. Bjarnason I, Hayllar J, MacPherson AJ and Russell AS: Side effects of non-steroidal anti-inflammatory drugs on the small and large intestine in humans. Gastroenterology 104: 18321847, 1993.

26. Keefe DM,Brealey J, Goland GJ and Cummins AG: Chemotherapy for cancer causes apoptosis that precedes hypoplasia in crypts of the small intestine in humans. Gut 47: 632-637, 2000.

27. Lam W, Bussom S, Guan1 F, Jiang Z, Zhang W, Gullen EA, Liu SH and Cheng YC: The four-herb Chinese medicine PHY906 reduces chemotherapy-induced gastrointestinal toxicity. Sci Transl Med 2: 45-59, 2010

28. Disi AM, Tamimib SO and Abuereish GM: Effects of Anchusa strigosa root aqueous extract on gastric ethanol-induced ulcer in laboratory animals. J Ethnopharmacol 60: 189-198, 1998.

29. Maity S, Vedasiromoni JR and Ganguly DK: Anti-ulcer effect of the hot water extract of black tea (Camellia sinensis). J Ethnopharmacol 46: 167-174, 1995.

30. Banerjee D, Maity B, Nag SK, Bandyopadhyay SK and Chattopadhyay S: Healing potential of Picrorhiza kurroa (Scrofulariaceae) rhizomes against indomethacin-induced gastric ulceration: a mechanistic exploration. BMC Complement Altern Med: Jan 31, 8: 3, 2008

31. McLean GW, Carragher NO, Avizienyte E, Evans J, Brunton VG and Frame MC: The role of focal - adhesion kinase in cancer - a new therapeutic opportunity. Nat Rev Cancer 5: 505-515, 2005. 